\title{
Citation:
}

Gurung, T.R., Stewart, R.A., Beal, C.D., Sharma, A.K., (2014) Smart meter enabled water end-use demand data: platform for the enhanced infrastructure planning of contemporary urban water supply networks, Journal of Cleaner Production.

DOI: http:/dx.doi.org/10.1016/j.jclepro.2014.09.054

\section{Smart meter enabled water end-use demand data: platform for the enhanced infrastructure planning of contemporary urban water supply networks}

\section{Authors:}

\section{Thulo Ram Gurung}

PhD Candidate, Griffith School of Engineering, Griffith University, Gold Coast Campus, QLD 4222, Australia, E-mail: ram.gurung@griffithuni.edu.au

\section{Rodney A. Ste wart*}

Associate Professor, Griffith School of Engineering, Griffith University, Gold Coast Campus, 4222, Australia, Phone: +61 75552 8778, E-mail: r.stewart@griffith.edu.au

*Corresponding author

\section{Cara D. Beal}

Research Fellow, Smart Water Research Centre, Griffith University, Southport, QLD 4222, Australia, Email: c.beal@griffith.edu.au

\section{Ashok K. Sharma}

Principal Research Scientist, CSIRO Land and Water, Highett, VIC 3190, Australia, E-mail: Ashok.sharma@csiro.au 


\begin{abstract}
Integrating alternative water supplies and water efficient appliances are proven strategies for reducing customers' average and peak demand on the cities mains water distribution infrastructure network. However, water utilities are yet to harness the potential of smart meters to build tailored daily diurnal demand patterns that reflect the consumption characteristics of individual developments that are increasingly applying alternative water sources and ultra-efficient appliances. This paper demonstrates how smart metering and water end-use data facilitates enhanced infrastructure planning of contemporary water supply schemes located in Queensland, Australia. To achieve research aims, extensive data received from high resolution smart meters fitted to a sample of 130 households was disaggregated into end use events (e.g. shower, dishwasher, etc.) and categorised into 48 thirty-minute time steps (i.e. daily diurnal demand) over the average day (AD) and peak day (PD). Moreover, these demand curves were also clustered according to water appliance stock efficiency ratings. Novel bottom-up end-use level models of demand were formulated representing scenarios of both single and multi-residential dwellings installed with combinations of water efficient appliances and rainwater tanks or greywater reuse. AD and PD diurnal demand patterns for these contemporary water scenarios were compared against the baseline scenario which represents the typical building code mandated dwelling constructed in the region of Queensland, Australia. Modelled demand curves for scenarios applying more efficient appliances in both dwelling types had lower peak demand than the baseline scenario by $13 \%$ and $6 \%$ for the AD and PD respectively, while scenarios also including rainwater tanks and greywater reuse (i.e. source substitution) resulted in peak reductions of $28 \%$ on the AD and $51 \%$ on the PD. The paper concludes with some implications for better handling the demand complexities of contemporary water supply schemes being developed by using smart meter data for the optimal planning of water infrastructure networks.
\end{abstract}

Keywords: smart meters, urban water, water end use, water micro-component, alternative water supplies, water efficient appliances, network modelling, demand patterns

\title{
List of abbreviations
}

AD Average day

kL Kilolitres

L/min Litres per min

$\mathrm{L} / \mathrm{h} \quad$ Litres per hour

L/hh/d Litres per household per day

$\mathrm{L} / \mathrm{p} / \mathrm{h} \quad$ Litres per person per hour

L/p/d L Litres per person per day

PHPDF Peak hour on the peak day factor

PD Peak day

PH Peak hour

QDC MP Queensland Development Code Mandatory Part

SEQ South East Queensland

SEQREUS South East Queensland Residential End Use Study

WELS Water Efficiency and Labelling Standards 


\section{Introduction}

\subsection{Alternative water supplies and water efficient appliances}

Water security is defined as 'the availability of an acceptable quantity and quality of water for health, livelihoods, ecosystems and production, coupled with an acceptable level of water-related risks to people, environments and economies' (Grey and Sadoff, 2007 p. 545). In Australia, the driest inhabited continent on the planet, water security is increasingly becoming one of the nation's greatest concerns, with population growth and climate change exacerbating the situation and further increasing the pressure on the existing water infrastructure (Gurung and Sharma, 2014). As water shortage is acknowledged to be a definite problem in the future, the attention has been drawn to alternative water solutions, ranging from large-scale schemes (e.g. desalination plants, dual water reticulation systems) to smaller ones in individual dwellings (e.g. rainwater tanks, on-site water-recycling plants) as well as the more socio-oriented demand management practices (e.g. water efficient appliances, leakage detection), with such measures aimed at reducing the dependence on the potable water grid (Britton et al. 2013; Sharma et al., 2008).

In Queensland, Australia, significant reductions in the dependency on the traditional potable water supply system have been achieved through implementation of water restrictions, tightened building code regulation and rebate programs for efficient water appliances (Makki et al., 2013; Umapathi et al., 2013). Prior to 2013, the now part-mandated Queensland Development Code (QDC) Mandatory Part (MP) 4.2, required households to save 70 kilolitres (kL) of mains water per year by using alternative water supplies, mainly through rainwater tanks and greywater reuse connected to toilets, washing machine cold water taps and external uses. The former approach was a popular option with rainwater tanks ownership rising from $22 \%$ to 36\% between 2007 and 2010 (ABS, 2013). Studies showed that rainwater tanks could potentially achieve annual mains water savings of 38-58 kL in single households (Beal et al., 2012; Chong et al., 2011; Domènech and Saurí, 2011; Ferguson, 2011; Umapathi et al. 2013) while potable savings of 7\% to $17 \%$ were reported for multi-storey residential buildings (Ghisi and Ferreira, 2007; Zhang et al., 2009). A number of other studies have also highlighted rainwater tank related issues including energy efficiency (Talebpour et al., 2014; Tjandraatmadja et al., 2011; Umapathi et al., 2013), economics assessment (Domènech and Saurí, 2011; Hall, 2013), tank optimisation (Imteaz et al., 2011, 2012) and water quality (Ahmed et al., 2014). Interest has also increased in the use of rainwater tanks in a communal setting, which lacks published studies. Recent studies include system monitoring of communal rainwater tanks in a residential area (Cook et al., 2013) and a commercial building (Cook et al, 2014), as well as an assessment of their economies of scale (Gurung and Sharma, 2014).

Greywater reuse involves the capture and treatment of used indoor household water, excluding toilets, for non-potable use and is another strategy for reducing mains water consumption. Various studies have reported potable water savings ranging between $25 \%$ and $50 \%$ achieved through the reuse of greywater, depending on their final end use and their scale of use (Friedler and Hadari, 2006; Ghisi and de Oliveira, 2007; Ghisi and Ferreira, 2007; Zhang et al., 2009, 2010). However, greywater systems used in individual compounds were shown to be uneconomical, with their high installation and operating costs resulting in long payback periods (Ghisi and de Olivieira, 2007; Mourad et al., 2011). Instead, greywater used on a larger scale was determined to be economically feasible (Ghisi and Ferreira, 2007; Mourad et al., 2011) and with prices potentially lower than potable water (Booker, 1999); however, the feasibility was dependent on the type of greywater treatment used (Friedler and Hadari, 2006; Mourad et al., 2011).

Ongoing work on demand management has seen a number of end-use studies focusing on household water consumption, both within Australia and overseas, utilising smart water meters. Such meters are able to record water consumption data at very fine scales (e.g. 0.01-0.02 litres per pulse) and intervals of five to ten seconds (e.g. Beal and Stewart, 2011; Willis et al., 2011) enabling the disaggregation of the various end uses through autonomous event recognition algorithms and associated software (Nguyen et al., 2014) and hence, their compositions of use around the households. End-use studies have revealed the vast majority of total 
household indoor demand to comprise of four main components; showers, clothes washers, toilets and taps. It has been generally acknowledged that replacing these end uses with higher efficiency appliances contribute to significant water savings (Beal and Stewart, 2011; Lee et al., 2011; Willis et al., 2013), with comparisons of water efficient homes against less efficient ones further validating their indoor water saving capabilities (Carragher et al., 2012). Replacing less efficient appliances with higher-efficiency ones resulted in mains water savings of $48 \%$ to $75 \%$ for shower heads, $65 \%$ for taps and $29 \%$ to $73 \%$ for clothes washer (Beal and Stewart, 2011; Willis et al., 2013), with front-loading clothes washers more efficient than toploaders (Beal and Stewart, 2011; EBMUD, 2008; Gato-Trinidad et al., 2011).

\subsection{Implications of potable water saving measures on peak demand}

Water demand varies through the day and is generally lowest over the night and highest in the morning and evening, the higher of which is termed the daily peak demand. This peak demand in the day is most critical on the PD of the year, which is usually driven by seasonable influences (e.g. extended dry weather causes sharp spike in outdoor demand). Studies on alternative water supplies and water efficient appliances have generally focussed on their ability to reduce total mains water consumption with the goal to extend the serviceability of dwindling bulk supply sources (e.g. dams), with few studies highlighting their role in reducing peak demand which is a key design parameter driving pipe network infrastructure planning and augmentations. Lucas et al. (2010) demonstrated reduced peaks of average daily demand patterns by $49 \%$ for a 50\% uptake of a trickle top-up rainwater system in a water supply zone. Similarly, Umapathi et al. (2013) reported a reduced hourly peak of $28 \%$ in a twenty home monitoring study of households fitted with a rainwater tank. The average daily demand pattern for a development using recycled water presented reduced peak flows $(\sim 35 \%)$ in mains water consumption against the total household demand (Willis et al., 2011). Drops in peak hour demand of $14 \%$ was also noted for water efficient households (Lucas et al., 2010) while a pair-wise comparison of water efficient and non-efficient households resulted in average daily peak hour reductions of $16 \%$ (Carragher et al, 2012). These studies have demonstrated the ability of water saving measures in reducing peak demands which have the potential to defer or eliminate planned augmentations of current supply network infrastructure and the related costs (Beal and Stewart, 2014; Carragher et al., 2012; Cole and Stewart, 2013).

\subsection{Water demand modelling of alternative water supplies and water efficient appliances}

Important parameters in the planning and design of the water supply network are the peak hour $(\mathrm{PH})$ on the peak day (PD) demand, which is the maximum day demand over a 12-month period, and the average day (AD) demand, which is the average water consumption over the same 12-month period. Peaking factors of $\mathrm{PD}$ are determined in relation to the $\mathrm{AD}$ demand, which are then fixed to historically determined water demand patterns for use in a water supply network model (GCW, 2009). However, these patterns may not be relevant to current trends as they are collected over long intervals, such as every three to five year periods. Furthermore, with the promotion of water efficient appliances and alternative water supplies, their impacts on the demand patterns are not fully known. In South East Queensland (SEQ), under the SEQ Code (2013), demand curves for alternative water supplies are constructed by adjusting the AD demand and peaking factors, which are then assigned to the same historically determined demand pattern. However, this method may not be reflective of the demand and usage patterns of the source substituted end uses. Thus, the identification of end-uses in households' diurnal patterns provide greater flexibility and a platform to more realistically model potable consumption patterns of households supplied by alternative water supplies. In this context, end-use studies using high resolution smart water meters provide useful information on the average daily usage characteristics of each end use which would be useful in developing water demand patterns of various water saving scenarios. 


\section{Research objectives}

Presently, there is a large volume of literature on the potable saving features of alternative water supplies and water efficient appliances, with few empirical studies reporting on their ability to reduce peak demand, which will ultimately reduce the need for costly water distribution network infrastructure augmentations. To address this gap in the literature, this study was conducted with the core objectives to:

- Determine mains (i.e. city supply) water savings, in terms of daily diurnal end use level demand on both the average and peak day, from using different star rated water appliances.

- Develop water demand profiles (AD and PD) for new single and multi-unit residential dwellings built following various scenarios of water efficiency and some alternative water supply through source substitution measures (i.e. rainwater or greywater).

- Compare AD and PD demand patterns for the contemporary water supply scenarios with the baseline scenario.

- Quantify reductions in AD and PD diurnal demand patterns for a particular development scenario (i.e. illustrative application of proposed planning approach).

\section{Research method}

\subsection{Study sample}

The study sample data for the research was obtained from the South East Queensland Residential End Use Study (SEQREUS) (Beal and Stewart, 2011) gathered over seven different periods. For each period, a twoweek continuous smart water meter dataset at very fine intervals ( 5 seconds) and resolution ( $0.014 \mathrm{~L} / \mathrm{pulse}$ ), was recorded. This allowed for the separation of the data into individual end uses using the event recognition software, Trace Wizard® (Aquacraft, 2010). Household stock survey was conducted for the homes from the SEQREUS study to determine the efficiency ratings of indoor water appliances. Gathered information included average flow rates of indoor taps and shower, water efficiency of washing machines and average toilet flush volumes. The appliances were rated with stars, according to the criteria set by the Water Efficiency and Labelling Standards (WELS); the more stars, the more water efficient the product. Smart water meter data from each household, for all indoor appliances, were also analysed to validate the survey against the WELS criteria. The sample sizes are shown in Table 1.

Table 1 Household sample size and recorded periods from the SEQREUS study

\begin{tabular}{lllll}
\hline Data & Period of analy sis & $\begin{array}{l}\text { No. of samples } \\
\text { (households) }\end{array}$ & $\begin{array}{l}\text { No. of } \\
\text { people }\end{array}$ & $\begin{array}{l}\text { Household } \\
\text { occupancy }\end{array}$ \\
\hline Winter 2010 & $14 / 06 / 2010$ to 27/06/2010 & 130 & 338 & 2.6 \\
Summer 2010-11 & $29 / 11 / 2010$ to $12 / 12 / 2010$ & 57 & 152 & 2.7 \\
Winter 2011 & $01 / 06 / 2011$ to $15 / 06 / 2011$ & 63 & 171 & 2.7 \\
Summer 2011-12 & $01 / 12 / 2011$ to $14 / 12 / 2011$ & 63 & 166 & 2.6 \\
Autumn 2012 & $18 / 03 / 2012$ to 31/03/2012 & 53 & 146 & 2.8 \\
Spring 2012 & $01 / 09 / 2012$ to $15 / 09 / 2012$ & 44 & 132 & 3.0 \\
Summer 2012-13 & $22 / 11 / 2012$ to $05 / 12 / 2012$ & 64 & 178 & 2.8 \\
\hline
\end{tabular}

*Reduced sample sizes due to Jan 2011 flooding and logger failure

Additionally, smart water meters measuring water consumption at a coarse level (5 L/pulse at hourly interval) for 336 multi-residential households in Hervey Bay, between 1 July 2008 and 1 July 2009, were included in the study. Although Hervey Bay does not lie within the SEQ region, household consumption is anticipated to be similar to SEQ, due to its coastal location and close proximity to SEQ. Owing to the low resolution of the data, it was not possible to segregate the data to their end uses, although consumption rates were defined for indoor $[\leq 300$ litres per hour $(\mathrm{L} / \mathrm{h})]$ and outdoor uses $(>300 \mathrm{~L} / \mathrm{h})$ (Cole and Stewart, 2013). Water consumption profiles for single-residential households in Hervey Bay were analysed in Gurung et al. (2014) and required results included in the paper. In this study context, single-residential household is 
defined as a premise of a single detached dwelling, while multi-residential is a premise consisting of three or more dwelling units, including townhouses, apartments and villas. Demand patterns were created at halfhourly time intervals, in line with local utilities standards, with the hourly Hervey Bay data interpolated at each interval for their conversion to half-hourly time-steps.

\subsection{Summary of demand pattern development}

Gurung et al. (2014) created a novel method of using up-to-date smart water meter data to define individual end-use's consumption patterns as a foundation for developing household water demand patterns. Each end use consumption pattern is converted into normalised end-use patterns by dividing demand at each time interval with average hourly demand (AD consumption divided by $24 \mathrm{~h}$ ). Average daily demands for individual end uses are estimated and applied to their respective normalised patterns to model their demand curves. The end-use demand curves are then combined to develop the final household demand pattern. A similar process is conducted to develop peak day demand patterns by increasing end-use demands and readjusting the normalised end-use pattern of outdoor use. A more detailed explanation of procuring demand curves using normalised end-use patterns is described in Gurung et al. (2014). To fulfil the paper's objectives, the methodology (Gurung et al., 2014) was applied in this study to model households' potable demand patterns for a range of water saving scenarios.

\subsection{Scenarios for modelling}

The study considered 4 scenarios for modelling water demand profiles in both single-residential and multiresidential dwellings. The modelled scenarios are shown in Table 2.

Table 2 Summary of modelled scenarios

\begin{tabular}{|c|c|c|}
\hline Scenario & Description & Water supply system specifications \\
\hline $\begin{array}{l}\text { Scenario } 1 \\
\text { (baseline) }\end{array}$ & $\begin{array}{l}\text { Households conforming to the region's mandatory } \\
\text { design code (i.e. QDC MP } 4.1 \text { for Queensland, } \\
\text { Australia) }\end{array}$ & $\begin{array}{l}\text { - 3-star taps, 3-star showers, 4-star clothes washer, } \\
\text { 4-star toilets }\end{array}$ \\
\hline Scenario 2 & Households fitted with water efficient appliances & $\begin{array}{l}\text { - >3-star taps, >3-star showers, >4-star clothes } \\
\text { washer, 4-star toilets (>4-star toilets not available) }\end{array}$ \\
\hline Scenario $3^{\S}$ & $\begin{array}{l}\text { Households fitted with water efficient appliances } \\
\text { and rainwater tanks }\end{array}$ & $\begin{array}{l}\text { - Water appliances as rated in Scenario } 2 \\
\text { - Rainwater tank supplyingtoilets, cold water tap to } \\
\text { clothes washer and outdoor taps }\end{array}$ \\
\hline Scenario 4 & $\begin{array}{l}\text { Households fitted with water efficient appliances } \\
\text { and greywater reuse facility }\end{array}$ & $\begin{array}{l}\text { - Water appliances as rated in Scenario } 2 \\
\text { - Grey water reuse supplying toilets, cold water tap to } \\
\text { clothes washer and outdoor taps }\end{array}$ \\
\hline
\end{tabular}

\subsubsection{Scenario 1 - Households conforming to QDC MP4.1 specifications (baseline)}

The QDC MP 4.1 mandates all new buildings to be water efficient and requires all indoor taps and showerheads to have at least a 3-star WELS rating, with toilets a minimum of a 4-star rating. These ratings formed the baseline efficiencies for this study. As clothes washer had not been assigned a WELS rating under the code, its median efficiency of a 4-star WELS rating (see Fig. 2) was used as the baseline efficiency.

Households from the SEQREUS study were clustered for each rated appliance and their demand profiles generated and compared against average demand profiles; the total demand over the seven periods divided by the total consuming population in those periods. The differences in consumption of each rated appliance against their respective average demand, which were assumed to be at current levels, were used to develop the demand patterns for households under the baseline scenario. 


\subsubsection{Scenario 2 - Households using more efficient water appliances}

Households with higher rated efficient appliances than baseline were clustered to generate their demand profiles. The consumption differences of higher rated appliances against their respective average demands were used to develop suitable demand patterns for each end use.

Although dishwashers are assigned a WELS rating, their low consumption of less than $2 \%$ of total household consumption (e.g. Beal and Stewart, 2011; Willis et al., 2011) will have minimal influences on overall consumption and peak flows for higher WELS rated dishwashers. Hence, this end use has not been considered in the cluster analysis.

Higher efficiency dual flush toilets (>4-star) currently do not comply with the requirements of the Australian Standards and cannot be registered for WELS (Schlunke et al., 2008). Although dual flush toilets $(4.5 / 3 \mathrm{~L})$ affixed with an integrated hand basin for greywater reuse can be registered for a WELS 5-star rating, they do not appear to be a popular option. In the study, there were no toilets which were more efficient that the baseline (4-star), which are at present the most efficient toilet available in Australia (Schlunke et al., 2008). Due to Australia Standards restrictions and lack of available samples for higher efficiency toilets, their analysis was not conducted.

\subsubsection{Scenario 3 - Water efficient households fitted with rainwater tanks}

Rainwater tank systems utilises mains water when they are at significantly low levels to ensure a continuous supply of water to the connected appliances. There are two types of rainwater systems; an automatic switch system and a trickle top-up system. Both systems works in the instance when the water in the tank falls below an acceptable level, with the former diverting mains water supply directly to the end uses, bypassing the tank and its pump systems, and the latter by delivering a fixed amount of mains water into the tank. However, in the event of the tank running dry for chronic periods, due to droughts or low rainfall levels, the two systems would provide limited benefits of reducing peak demands. The potable demand profile for the automatic switch system would be no different to a household without a rainwater tank, while in a trickle top-up system, tank replenishment could coincide with the peak demand time, thereby having limited effects on reducing it.

No considerations are currently in place in designing rainwater tanks to reduce mains supply peak flows, especially under constant drought conditions, which, over a wider scale, would potentially provide notable network benefits. Consequently, the study proposes an alternative to the traditional designs; a trickle top-up rainwater tank system fitted with an electronic timer-based valve. The electronic valve will be programmed to replenish the tanks only during periods of low household demand, particularly overnight and in the afternoon, when a trigger level in the tank, equivalent to at least a day's supply, has been reached. Mains water top up would be distributed overnight at a constant flow, with total volume equivalent to average daily demand of the tank's connected appliances, and further top up done in the afternoon if required. Such a design would help reduce daily peak flows even during low rainfall periods, while also ensuring sufficient water for the following day. In periods of high water usage, especially on peak day, the top up programmed for the afternoon would ensure that the tank meets the day's demand. The schematic of the proposed system is shown in Fig. 1. 


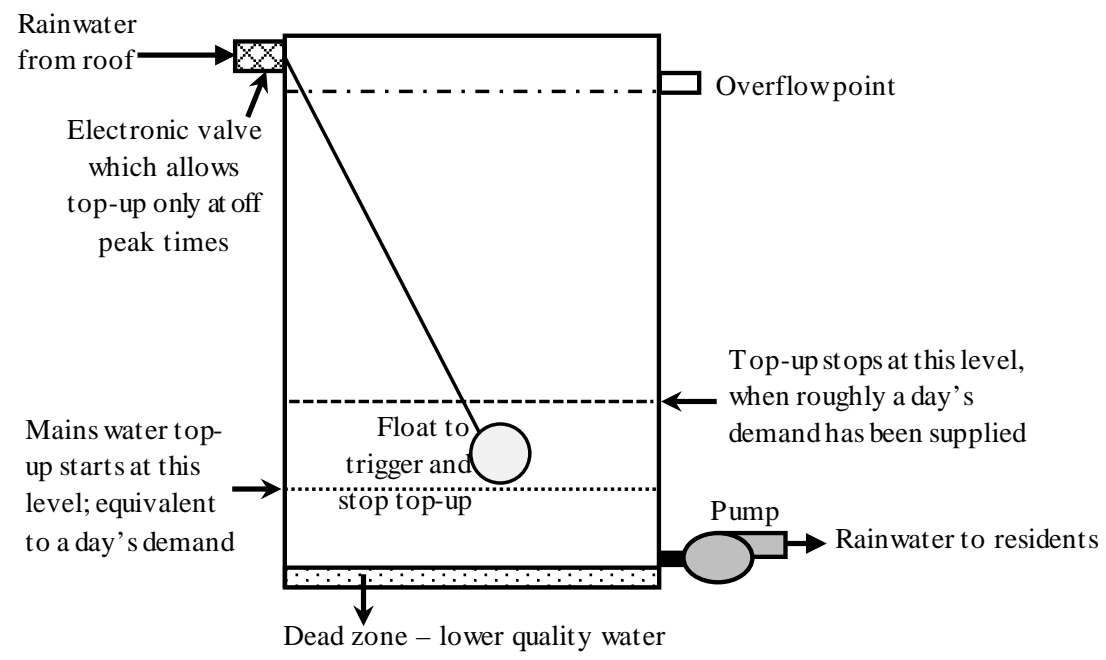

Fig. 1 Schematic of rainwater tank configuration

For the objectives of the study, the proposed configuration will be used to model the potable demand profile for rainwater tanks supplying to toilets, cold water laundry and outdoor use. These end uses are widely acceptable rainwater uses across most of Australia and abroad (e.g. Beal et al., 2012; Domènech and Saurí, 2011; Ferguson, 2011; Ghisi and de Oliveira, 2007).

\subsubsection{Scenario 4 - Water efficient households fitted with greywater recycling}

Greywater for unrestricted non-potable uses in toilets, clothes washing and outdoor purposes require their treatment systems to be highly effective in removing organic and microbial contaminants (Li et al, 2009). Hence, the study considers the use of biological treatment and membrane filtration systems, such as rotating biological contactor or membrane bioreactor, as the chosen greywater treatment system. Although the application of such greywater systems in single households is economically unfeasible (Friedler and Hadari, 2006; Mourad et al., 2011), their mains diurnal demand pattern is still developed for comparison purposes.

In Australia, greywater from kitchen sinks and dishwashers are not recommended for use as they are contaminated with grease, bacteria and chemicals which can promote and support the growth of microorganisms and solidify, causing blockages in the greywater system (DIP, 2008; DOH, 2010). For these reasons, greywater from kitchen sinks', which accounts for $5 \%$ of total household consumption (ChristovaBoal et al., 1996) ( 40\% of tap use), and dishwashers were excluded from greywater reuse.

\section{Developing bottom-up AD and PD demand patterns for scenarios}

\subsection{Analysis of cluster scale indoor water appliances for different rated efficiencies}

Appliances were clustered under three efficiency rating categories for each appliance: 1) baseline efficiency, 2) more than baseline efficiency and 3) less than baseline. Due to the lack of samples for toilets that had an efficiency at or greater than the baseline efficiency category, the <baseline efficient toilets cluster (i.e. toilets $<4$-star) was further divided to a 3-star and $<3$-star toilet cluster, in order to better understand the influence of efficiency on toilet cisterns peak flows. Consumption patterns for each cluster category and appliance were then generated (Table 3).

Table 3 Appliance cluster categories

\begin{tabular}{|c|c|c|c|c|c|}
\hline End-use & Descriptor & \multicolumn{2}{|c|}{$<$ Baseline efficiency } & Baseline efficiency & >Baseline efficiency \\
\hline \multirow[t]{2}{*}{ Clothes washer } & Star rating & \multicolumn{2}{|l|}{$<4$-star } & 4-star & $>4$-star \\
\hline & Flow category (avg. L/wash)* & \multicolumn{2}{|c|}{$104-118$} & $65-72$ & $50-58$ \\
\hline \multirow[t]{2}{*}{ Shower } & Star rating & \multicolumn{2}{|l|}{$<3$-star } & 3-star & $>3$-star \\
\hline & Flow category (L/min) & \multicolumn{2}{|l|}{$>9.0$} & $7.5-9.0$ & $\leq 7.5$ \\
\hline \multirow[t]{2}{*}{ Toilet } & Star rating & $<3$-star & 3-star & 4-star & $>4$-star \\
\hline & Flow category (L/flush)** & $>4.0$ & $3.5-4.0$ & $3.0-3.5$ & N/A \\
\hline Taps & Star rating & \multicolumn{2}{|l|}{$<3$-star } & 3-star & $>3$-star \\
\hline
\end{tabular}


*average consumption per wash over all analysed periods, **average consumption for dual flush toilet is taken as average of one full flush and four half flushes

The SEQREUS only monitored households built before the implementation of the QDC MP 4.1. Hence, there was generally a low uptake of indoor water efficient appliances within the study sample as householders were not mandated to install such water saving appliances. The average population uptakes (in percentage) for the appliances over the seven periods are shown in Fig. 2.

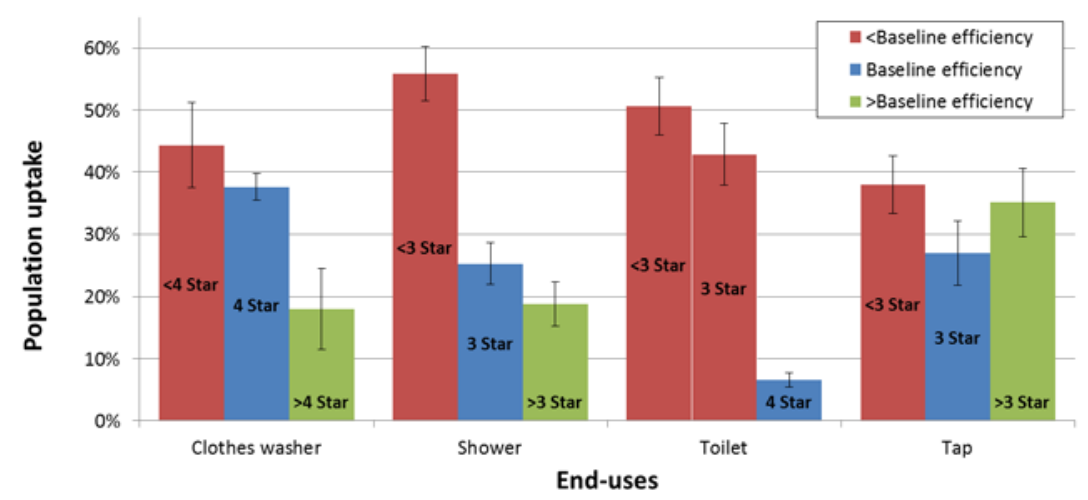

Note: Error bars indicate standard deviation of uptake for the seven recorded periods

Fig. 2 Population up take of rated appliances

Demand patterns of efficiency rated end-uses, in litres per person per hour (L/p/h), are illustrated in Fig. 3. There are similar and consistent patterns for each appliance, with peak demands occurring mainly in the mornings; clothes washer peaks at 9 am; shower and toilet peaks around 7:30 am and tap peaks between 8 am to 8:30 am, with a similar peak pattern at $7 \mathrm{pm}$.
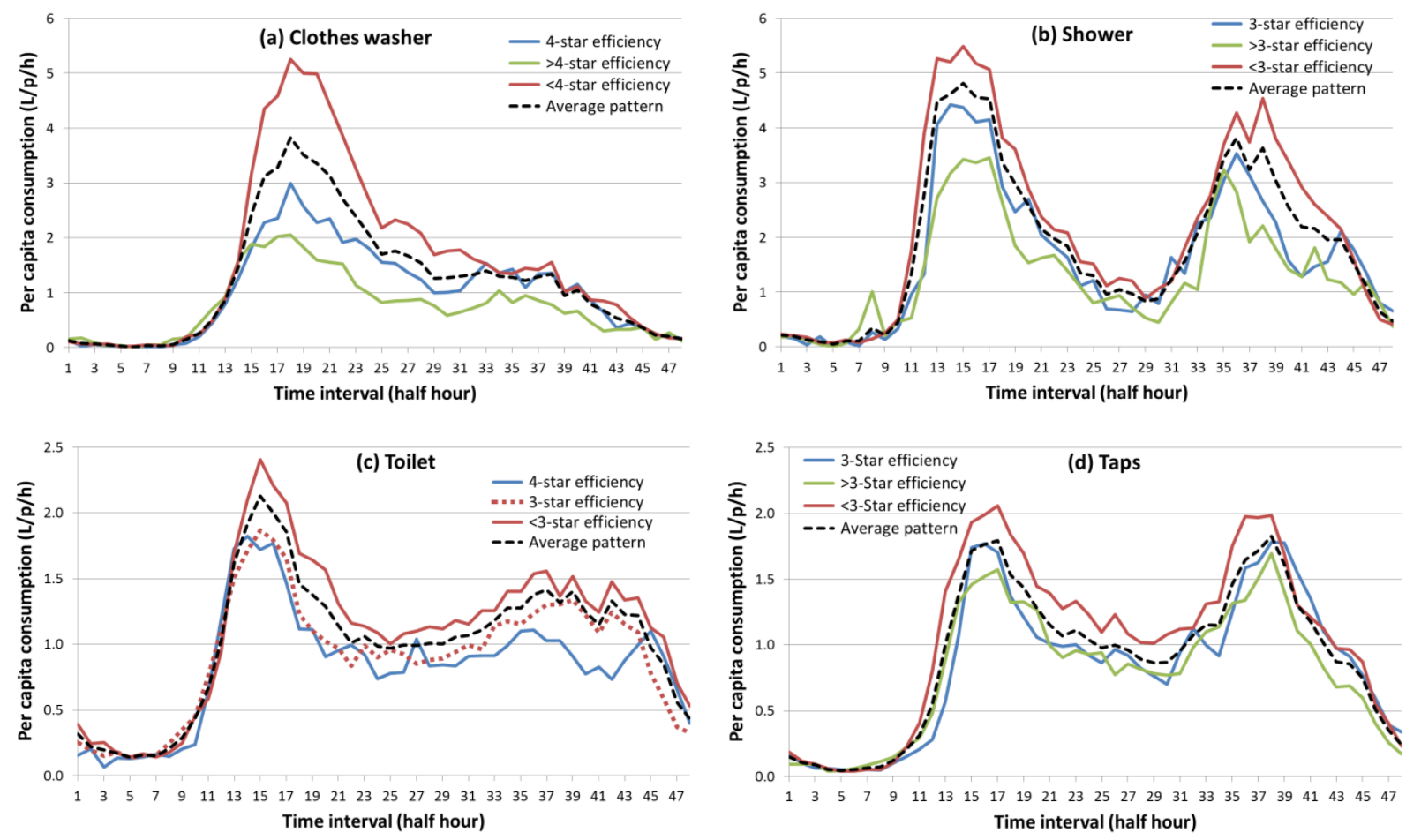

Fig. 3 Diurnal demand patterns of efficiency rated appliances

Comparisons in average demand, in litres per person per day $(\mathrm{L} / \mathrm{p} / \mathrm{d})$, and peak demand $(\mathrm{L} / \mathrm{p} / \mathrm{h})$, against the average daily consumption from all end-use reads are presented in Table 4 . The <baseline efficient toilets (<4-star) had similar average demand and peak demand to the average daily demand as the lower consumption of 3-star toilets offset the much higher consumption of the <3-star toilets (see Fig. 3c). 
Nevertheless, Fig. 3c shows higher peak demand for lower rated toilets. Clothes washer in the <baseline efficiency cluster $(<4$-star) had the highest increase in average demand and peak demand of $29.5 \%$ and $37.3 \%$, respectively. The <baseline efficient taps and showers (<3-star each) had higher average and peak demands of no less than $13.9 \%$.

The largest reduction in average demand and peak demand was observed for clothes washer, with reductions of $16.3 \%$ and $21.8 \%$ respectively in the baseline cluster (4-star) and $38.6 \%$ and $46.3 \%$ reductions in the $>$ baseline cluster (>4-star). The >baseline efficient showers (>3-star) had drops in average demand and peak demand of approximately $28 \%$, while the >baseline efficient taps (>3-star) reduced by $11.9 \%$ each. Baseline efficiency toilets (4-star) had reductions of $17.2 \%$ and $14.5 \%$ for average demand and peak demand, respectively.

Table 4 Mains water and peak demand differences of rated appliances against average demand

\begin{tabular}{|c|c|c|c|c|c|c|c|}
\hline \multirow[b]{2}{*}{ End-use } & \multirow{2}{*}{$\begin{array}{l}\text { Average* } \\
\text { Average } \\
\text { demand } \\
(\mathrm{L} / \mathrm{p} / \mathrm{d})\end{array}$} & \multicolumn{2}{|c|}{$<$ Baseline efficiency } & \multicolumn{2}{|c|}{ Baseline efficiency** } & \multicolumn{2}{|c|}{ >Baseline efficiency } \\
\hline & & $\begin{array}{l}\text { Average } \\
\text { demand } \\
(\mathrm{L} / \mathrm{p} / \mathrm{d})\end{array}$ & $\begin{array}{l}\text { Average } \\
\text { demand } \\
\text { diff. (\%) }\end{array}$ & $\begin{array}{l}\text { Average } \\
\text { demand } \\
(\mathrm{L} / \mathrm{p} / \mathrm{d})\end{array}$ & $\begin{array}{l}\text { Average } \\
\text { demand } \\
\text { diff. (\%) }\end{array}$ & $\begin{array}{l}\text { Average } \\
\text { demand } \\
(\mathrm{L} / \mathrm{p} / \mathrm{d})\end{array}$ & $\begin{array}{l}\text { Average } \\
\text { demand } \\
\text { diff. (\%) }\end{array}$ \\
\hline Toilet & 24.1 & 24.4 & $1.2 \%$ & 20.0 & $-17.2 \%$ & N/A & - \\
\hline Clothes washer & 29.3 & 38.0 & $29.5 \%$ & 24.6 & $-16.3 \%$ & 18.0 & $-38.6 \%$ \\
\hline Shower & 45.2 & 52.2 & $15.3 \%$ & 39.7 & $-12.4 \%$ & 32.3 & $-28.6 \%$ \\
\hline Taps & 21.7 & 24.9 & $15.1 \%$ & 20.4 & $-5.8 \%$ & 19.1 & $-11.9 \%$ \\
\hline End uses & $\begin{array}{l}\text { Peak } \\
(\mathrm{L} / \mathrm{p} / \mathrm{h})\end{array}$ & $\begin{array}{l}\text { Peak } \\
(\mathrm{L} / \mathrm{p} / \mathrm{h})\end{array}$ & $\begin{array}{l}\text { Peak diff. } \\
(\%)\end{array}$ & $\begin{array}{l}\text { Peak } \\
(\mathrm{L} / \mathrm{p} / \mathrm{h})\end{array}$ & $\begin{array}{l}\text { Peak diff. } \\
(\%)\end{array}$ & $\begin{array}{l}\text { Peak } \\
(\mathrm{L} / \mathrm{p} / \mathrm{h})\end{array}$ & $\begin{array}{l}\text { Peak diff } \\
(\%)\end{array}$ \\
\hline Toilet & 2.13 & 2.16 & $1.3 \%$ & 1.82 & $-14.5 \%$ & N/A & - \\
\hline Clothes washer & 3.83 & 5.25 & $37.3 \%$ & 2.99 & $-21.8 \%$ & 2.06 & $-46.3 \%$ \\
\hline Shower & 4.82 & 5.49 & $13.9 \%$ & 4.43 & $-8.1 \%$ & 3.46 & $-28.2 \%$ \\
\hline Taps & 1.79 & 2.06 & $14.8 \%$ & 1.77 & $-1.4 \%$ & 1.57 & $-12.2 \%$ \\
\hline
\end{tabular}

*average daily consumption from all recorded periods, **appliances conforming to QDC MP 4.1 specified efficiencies

These results, based on directly measured water demand, provide further evidence of the capacity of waterefficient technology to reduce average and peak mains water demand. For all water appliances, there were progressive reductions in average demand and peak demand as efficiency increased, demonstrating the use of this empirical information for underpinning the subsequent modelling of water demand profiles presented below.

\subsection{Indoor demand modelling}

\subsubsection{Average day consumption demands}

In SEQ, the utility has assigned an AD consumption of $220 \mathrm{~L} / \mathrm{p} / \mathrm{d}$ (SEQ Code, 2013), with $160 \mathrm{~L} / \mathrm{p} / \mathrm{d}$ estimated for indoor use and $60 \mathrm{~L} / \mathrm{p} / \mathrm{d}$ for outdoor use (QWC, 2010). Average consumption values for each end use were estimated by distributing the utility's $\mathrm{AD}$ indoor demand to their percentage distribution obtained from Gurung et al. (2014). Baseline (Scenario 1) and higher efficiency (Scenario 2) water demands were estimated by decreasing the estimated average end-use demands with their respective consumption differences from the results of the cluster scale analysis (shown in Table 4). Rainwater (Scenario 3) and greywater (Scenario 4) replaced toilets and cold water for clothes washer, which is estimated to be $75 \%$ of total laundry consumption (EBMUD, 2008). Table 5 shows the AD indoor end-use demand values used to model the demand profiles for each scenario. 
Table 5 Indoor water consumptions estimated for the various scenarios

\begin{tabular}{|c|c|c|c|c|c|c|c|c|}
\hline \multirow[b]{2}{*}{ End-use } & \multicolumn{2}{|c|}{ Utility demand } & \multicolumn{2}{|c|}{$\begin{array}{c}\text { Scenario } 1 \\
\text { Baseline efficiency }\end{array}$} & \multicolumn{2}{|c|}{$\begin{array}{c}\text { Scenario } 2 \\
>\text { Baseline efficiency }\end{array}$} & \multicolumn{2}{|c|}{$\begin{array}{c}\text { Scenarios } 3 \text { and } 4 \\
\text { Rainwater and } \\
\text { greywater reuse* }\end{array}$} \\
\hline & $\begin{array}{l}\text { Average } \\
\text { demand } \\
(\mathrm{L} / \mathrm{p} / \mathrm{d})\end{array}$ & $\begin{array}{l}\text { Indoor } \\
\text { distribution } \\
(\%)\end{array}$ & $\begin{array}{l}\text { Modelled } \\
\text { demand } \\
(\mathrm{L} / \mathrm{p} / \mathrm{d})\end{array}$ & $\begin{array}{l}\text { Reduction } \\
\text { (\%) }\end{array}$ & $\begin{array}{l}\text { Modelled } \\
\text { demand } \\
(\mathrm{L} / \mathrm{p} / \mathrm{d})\end{array}$ & $\begin{array}{l}\text { Reduction } \\
\text { (\%) }\end{array}$ & $\begin{array}{l}\text { Modelled } \\
\text { demand** } \\
(\mathrm{L} / \mathrm{p} / \mathrm{d})\end{array}$ & $\begin{array}{l}\text { Reduction } \\
(\%)\end{array}$ \\
\hline Toilet & 29.3 & $18.3 \%$ & 24.3 & $17.2 \%$ & 24.3 & $17.2 \%$ & 0.0 & $100.0 \%$ \\
\hline Clothes washer & 35.3 & $22.1 \%$ & 29.6 & $16.3 \%$ & 21.7 & $38.6 \%$ & 5.4 & $75.0 \%$ \\
\hline Shower & 56.6 & $35.4 \%$ & 49.6 & $12.4 \%$ & 40.4 & $28.6 \%$ & 40.4 & $0.0 \%$ \\
\hline Dishwasher & 2.8 & $1.7 \%$ & 2.8 & $0.0 \%$ & 2.8 & $0.0 \%$ & 2.8 & $0.0 \%$ \\
\hline Tap & 26.6 & $16.6 \%$ & 25.1 & $5.8 \%$ & 23.4 & $11.9 \%$ & 23.4 & $0.0 \%$ \\
\hline Bath & 2.4 & $1.5 \%$ & 2.4 & $0.0 \%$ & 2.4 & $0.0 \%$ & 2.4 & $0.0 \%$ \\
\hline Leak & 7.0 & $4.4 \%$ & 7.0 & $0.0 \%$ & 7.0 & $0.0 \%$ & 7.0 & $0.0 \%$ \\
\hline
\end{tabular}

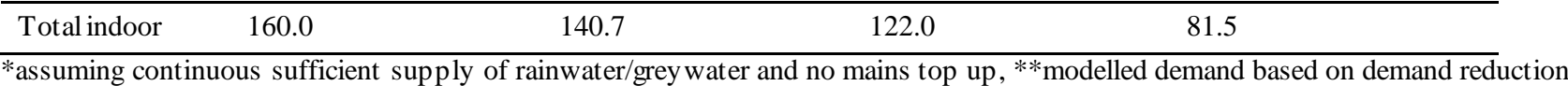
of Scenario 2

\subsubsection{Multi-residential indoor water use analysis}

The coarse nature of the smart water meter data from households in the Hervey Bay sample meant segregation of individual end-uses was not possible, with the exception of indoor and outdoor uses. Indoor water consumption was similar for multi-residential and single-residential households, at $142 \mathrm{~L} / \mathrm{p} / \mathrm{d}$ and 147 L/p/d respectively. Both normalised indoor demand patterns (Fig. 4) showed matching consumption trends. Loh and Coghlan (2003) reported little variance in indoor consumptions for single and multi-residential households in Perth and proportions of each indoor end use were found to be identical. These examples provide evidence to suggest that the usage patterns and distributions of indoor end-uses in both dwelling types are similar. Hence, normalised end-use patterns from single-residential households, developed in Gurung et al. (2014), were used to model the various water demand profiles for both dwelling types.

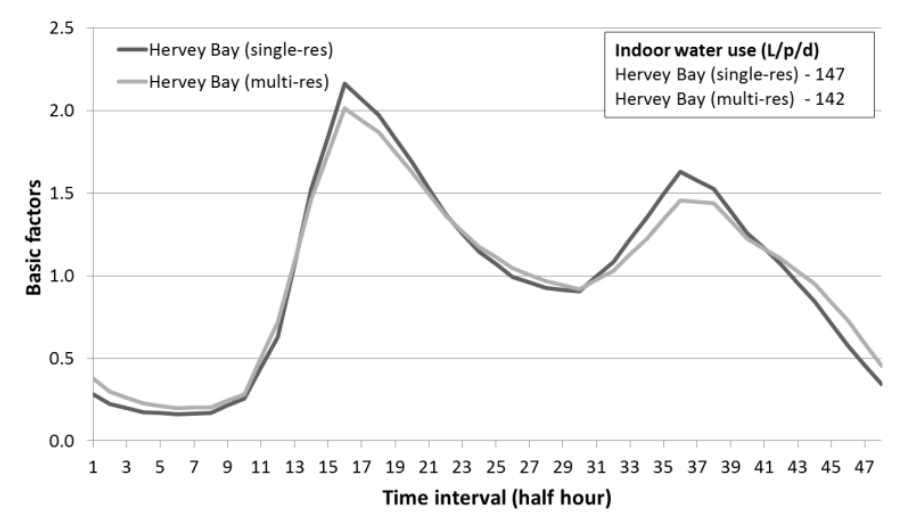

Fig. 4 Indoor water consumption patterns for single and multi-residential households

\subsubsection{Multi-residential peak day indoor consumption}

Ideally, a continuous year's high resolution consumption data is preferred for obtaining end-use PD demand profiles, however in the absence of this, the coarse-natured Hervey Bay smart water dataset was used to analyse indoor and outdoor PD. Indoor PD demand for multi-residential homes in Hervey Bay was 8\% higher than the $\mathrm{AD}$ demand while the PD peak demands in the morning and evening were higher than the $\mathrm{AD}$ peak demands by $7 \%$ each. To allow for a conservative approach in estimating PD indoor consumption profiles in multi-residential homes (due to the absence of measured end-use data), consumption for each indoor end-use was increased by $10 \%$ of their $\mathrm{AD}$ demand. In single-residential households, indoor demand 
on the PD was higher than the AD demand by $18 \%$, while demand at each time interval were on average $20 \%$ higher. Based on the observed differences, an increase of $20 \%$ of $\mathrm{AD}$ demand was chosen to model the associated PD demand curves for single-residential dwellings (Gurung et al., 2014).

\subsection{Outdoor water de mand modelling}

\subsubsection{Average day outdoor water consumption profiles}

Property size is an influencing factor on outdoor consumption with larger properties typically having a higher demand than smaller properties (Cole and Stewart, 2013). The relationship between property size and outdoor demand in Hervey Bay is shown in Table 6 (Cole and Stewart, 2013). With new properties now being built on smaller lots, the information on average day external water consumption is essential in modelling overall water demand profiles, as outdoor use is reported to be the main driver of peak demands (Beal and Stewart, 2014; Cole and Stewart, 2013; Willis et al., 2011).

Table 6 Outdoor water demand of various sized properties compared against average single-residential households in Hervey Bay (Cole and Stewart, 2013)

\begin{tabular}{lllll}
\hline \multirow{2}{*}{ Dwelling type } & Dwelling size & $\begin{array}{l}\text { Outdoor demand per } \\
\text { household per day (L/h//d) }\end{array}$ & $\begin{array}{l}\text { Outdoor demand per } \\
\text { person per day (L/p/d) }\end{array}$ & $\begin{array}{l}\text { Demand } \\
\text { difference }\end{array}$ \\
\hline \multirow{5}{*}{ Single-residential } & Average & 116.5 & 43.2 & - \\
& Largest $\left(3155 \mathrm{~m}^{2}\right)$ & 194.2 & 71.9 & $66.7 \%$ \\
& Medium-large $\left(1392 \mathrm{~m}^{2}\right)$ & 143.7 & 53.2 & $23.3 \%$ \\
& Medium-small $\left(832 \mathrm{~m}^{2}\right)$ & 83.6 & 31.0 & $-28.2 \%$ \\
& Smallest $\left(521 \mathrm{~m}^{2}\right)$ & 45.9 & 17.0 & $-60.6 \%$ \\
Multi-residential & $<300 \mathrm{~m}^{2}$ & 26.9 & 12.8 & $-70.2 \%$ \\
\hline
\end{tabular}

To reflect the lower external water use for smaller sized households, outdoor water demand was reduced by $60 \%$ and $70 \%$ for single-residential and multi-residential dwellings, respectively, based on the differences in demand shown in Table 6. The resulting outdoor demands of $24 \mathrm{~L} / \mathrm{p} / \mathrm{d}$ and $18 \mathrm{~L} / \mathrm{p} / \mathrm{d}$ were used to model outdoor demand profiles for their corresponding property types.

In multi-residential homes, the $\mathrm{AD}$ external water use occurred mainly in the morning with less use in the evening; conversely, single-residential homes showed a main outdoor demand peak in the evening and a smaller peak in the morning (see Fig. 5). This highlighted the difference in outdoor usage patterns in both dwelling types, of which may be attributed to differences in consumers' lifestyles and behaviours (Beal and Stewart, 2014). For example, the prevalence of stay-at-home parents or retirees living in multi-residential dwellings might result in more outdoor water being used earlier in the day than in the evening.

\subsubsection{Peak day outdoor water consumption profiles}

On the PD, the demand pattern for outdoor water use in multi-residential households was similar to the AD demand with more water used externally in the morning than in the evening. While the timing of the outdoor AD peak coincided with the indoor peak demand in the morning $(8 \mathrm{am})$, the outdoor PD peak occurred slightly later $(10 \mathrm{am})$ and outside of indoor peak demand time. The delay in peak demand could be due to the PD occurring over the weekend, when householders are free to use water for outdoor activities (e.g. washing car, gardening) throughout the day, and may also explain the relatively high water usage in the afternoon (see Fig. 5b).

The timing of the outdoor and indoor peak demands is important as their concurrence results in the maximum peak occurring in the total demand curve. To ensure maximum peak occurs on PD for multiresidential homes, the outdoor normalised AD curve was used as a base to model the PD curve. Related to this, the following peak factors were used: the PD factor (PDF), which is the ratio of outdoor water use on the $\mathrm{PD}$ to the $\mathrm{AD}$, and the $\mathrm{PH}$ on the $\mathrm{PD}$ factor (PHPDF), which is the ratio of the $\mathrm{PH}$ consumption on the 
PD to the average hour consumption on the AD. The PD outdoor water profiles of multi-residential dwellings, which had PDF and PHPDF of 4.07 and 9.08 respectively, were modelled by scaling these factors to the normalised $\mathrm{AD}$ outdoor consumption profile, using the EXCEL ${ }^{\mathrm{TM}}$ Solver method presented in Gurung et al. (2014). The outdoor demand profile for single-residential households had PDF of 3.63 and PHPDF of 12.42, with the peak occurring in the evening (6 pm), and were presented in Gurung et al. (2014). The higher PHPDF for single-residential dwellings is due to the much higher $\mathrm{PH}$ water volume used, in relation to the average outdoor demand, which is much higher compared to the $\mathrm{PH}$ demand for multi-residential households. The modelled outdoor demand profiles for both dwellings are shown in Fig. 5.
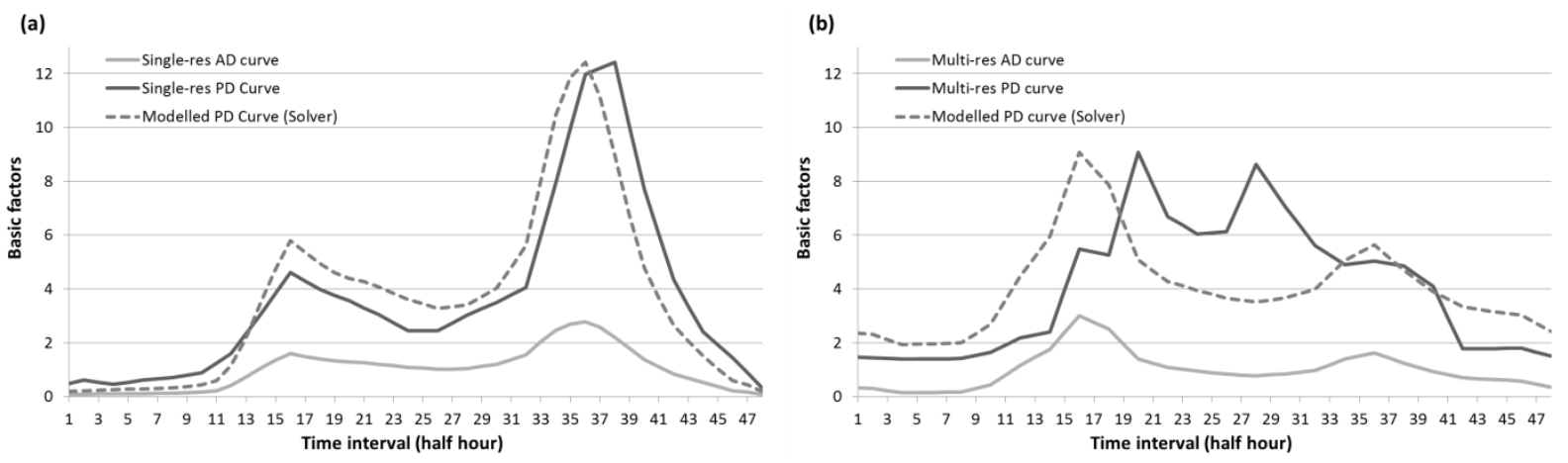

Fig. 5 Modelled outdoor consumption patterns for (a) single-residential and (b) multi-residential households

\subsection{Rainwater tank top-up configuration}

The rainwater tank trickle top-up configuration in the study was designed to allow top-up only during offpeak hours. Rainwater tank AD demands were $64.5 \mathrm{~L} / \mathrm{p} / \mathrm{d}$ for single-residential homes and $58.5 \mathrm{~L} / \mathrm{p} / \mathrm{d}$ for multi-residential homes (see Table 7). The volumes were distributed evenly overnight between $8 \mathrm{pm}$ and 6 am (over 10 hours) at top-up rates of $6.5 \mathrm{~L} / \mathrm{p} / \mathrm{h}$ and $5.9 \mathrm{~L} / \mathrm{p} / \mathrm{h}$ for single and multi-residential households, respectively, to ensure that the tank's demand is met the following day.

Table 7 AD and PD demand of end-uses supplemented by rainwater tank

\begin{tabular}{lllll}
\hline \multirow{2}{*}{ End-use } & \multicolumn{2}{c}{ Single-residential } & \multicolumn{2}{c}{ Multi-residential } \\
& $\begin{array}{l}\text { AD demand } \\
(\mathrm{L} / \mathrm{p} / \mathrm{d})\end{array}$ & $\begin{array}{l}\text { PD demand } \\
(\mathrm{L} / \mathrm{p} / \mathrm{d})\end{array}$ & $\begin{array}{l}\text { AD demand } \\
(\mathrm{L} / \mathrm{p} / \mathrm{d})\end{array}$ & $\begin{array}{l}\text { PD demand } \\
(\mathrm{L} / \mathrm{p} / \mathrm{d})\end{array}$ \\
\hline Toilet & 24.3 & 29.1 & 24.3 & 26.7 \\
Clothes washer (cold) & 16.3 & 19.5 & 16.3 & 17.9 \\
Outdoor & 24.0 & 87.1 & 18.0 & 73.2 \\
\hline Total tank demand & 64.6 & 135.7 & 58.6 & 117.8 \\
\hline
\end{tabular}

Modelling indicates that on the PD, the overnight top-up is insufficient to provide for the additional demand and a second top-up in the lower afternoon periods, between $12 \mathrm{pm}$ and $4 \mathrm{pm}$, would be required. The additional top up, along with the tank's one day backup supply, ensures demand is met and the tank does not run dry on the PD. As normal demand resumes, the tank is reset to usual operating conditions.

\subsection{Greywater reuse water balance}

The AD greywater production is predicted to satisfy the AD demand, however this is not the case during PD demand where greywater production is insufficient (Table 8). Simple water balance calculations 
demonstrated that a storage volume equivalent to one day's greywater production, together with the production on PD, would be a sufficient supply for a PD demand scenario (data not shown).

Table 8 Grey water production and AD and PD demand

\begin{tabular}{lllll}
\hline \multirow{2}{*}{ End-use } & \multicolumn{2}{c}{ Single-residential } & \multicolumn{2}{c}{ Multi-residential } \\
& $\begin{array}{l}\text { AD demand } \\
(\mathrm{L} / \mathrm{p} / \mathrm{d})\end{array}$ & $\begin{array}{l}\text { PD demand } \\
(\mathrm{L} / \mathrm{p} / \mathrm{d})\end{array}$ & $\begin{array}{l}\text { AD demand } \\
(\mathrm{L} / \mathrm{p} / \mathrm{d})\end{array}$ & $\begin{array}{l}\text { PD demand } \\
(\mathrm{L} / \mathrm{p} / \mathrm{d})\end{array}$ \\
\hline Clothes washer & 21.7 & 26.0 & 21.7 & 23.8 \\
Shower & 40.4 & 48.5 & 40.4 & 44.5 \\
Tap* & 14.1 & 16.9 & 14.1 & 15.5 \\
Bath & 2.4 & 2.9 & 2.4 & 2.6 \\
\hline Total grey water produced & 78.5 & 94.2 & 78.5 & 86.4 \\
\hline Toilet & 24.3 & 29.1 & 24.3 & 26.7 \\
Clothes washer (cold) & 16.3 & 19.5 & 16.3 & 17.9 \\
Outdoor use & 24.0 & 87.1 & 18.0 & 73.20 \\
\hline Total grey water demand & 64.5 & 135.7 & 58.5 & 117.8 \\
\hline *Tap excludes kitchen sink $(40 \%$ of tap use) & & &
\end{tabular}

\section{Comparative assessment of modelled scenarios’ AD and PD demand patterns}

The normalised indoor end-use patterns for single-residential households produced in Gurung et al. (2014) were used for generating indoor demand patterns for both single and multi-residential dwellings in this study, as discussed in Section 4.2.2. Outdoor demand curves for both dwellings were developed using their corresponding modelled base AD curves (Fig. 5). By applying revised water consumption profiles for each end-use category to their respective normalised patterns, their final demand patterns were created. The demand profiles for the proposed scenarios were developed by combining these demand curves.

A comparison of modelled consumption patterns for baseline (Scenario 1) against water saving scenarios (Scenarios 2 to 4) illustrates the reductions in peak demand on both the AD and PD for single and multiresidential dwelling types (Fig. 6). AD peak demand reduced by $13 \%$ in both single-residential and multiresidential households for Scenario 2, while the PH on PD demand reduced by 6\% and 10\% respectively. Due to clustered sub-sample size limitations, it was not possible to determine the reduction in potable consumption for the highest WELS rated appliances; that is $>3$-star showers ( $>4.5 \mathrm{~L} / \mathrm{min}$ but $\leq 6 \mathrm{~L} / \mathrm{min}$ ), 5 star washing machines and 6-star taps. The results of the cluster scale analysis showed reduced peak demand for higher efficiency indoor appliances, which suggests that households using the maximum rated indoor water appliances would likely realise further reductions in peak demand.
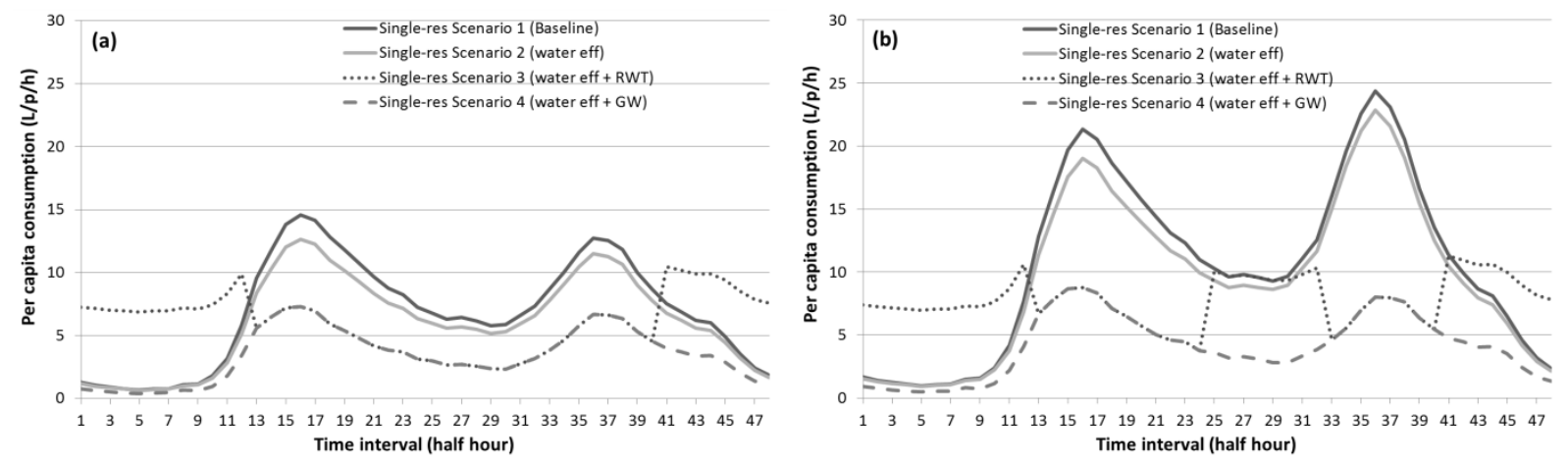

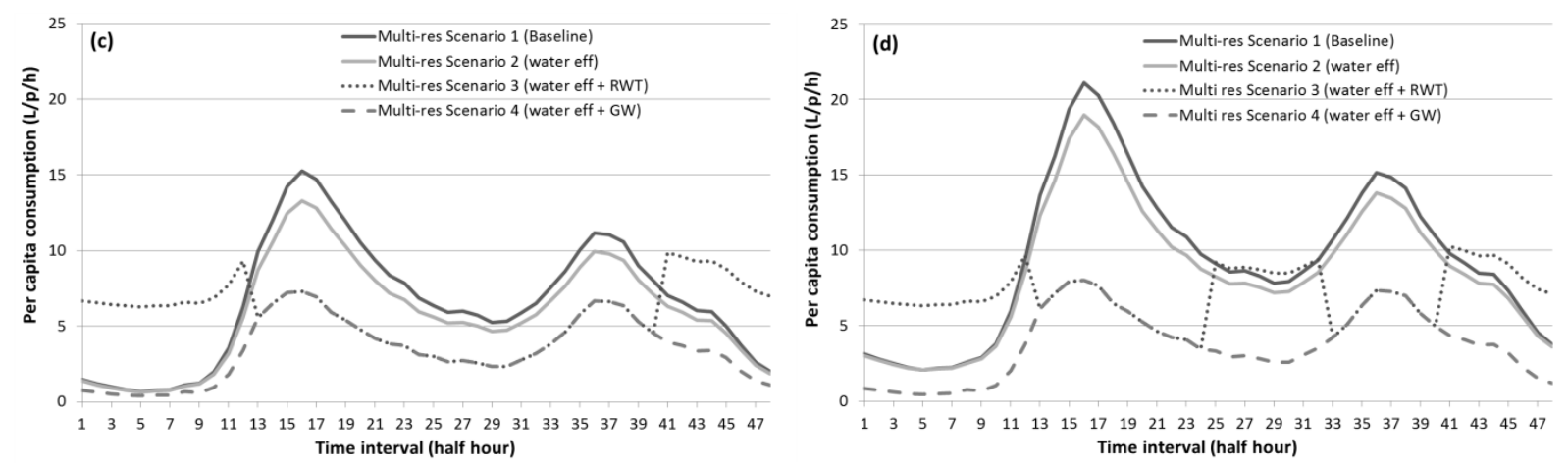

Fig. 6 Modelled mains water consumption profiles for the various water saving scenarios for (a) single-residential on AD (b) singleresidential on PD (c) multi-residential on AD (d) multi-residential on PD

While peak demand for modelled AD demand curves occurred at similar times in the two dwelling types, $\mathrm{PH}$ for modelled PD demand curves in both Scenarios 1 and 2 occurred in the evening and morning, for single and multi-residential dwellings, respectively. The timings of $\mathrm{PH}$ demand for both dwelling types corresponded with the timings of the $\mathrm{PH}$ demands for the respective outdoor use. This highlights their influence on the peaks of the modelled PD curves and is supported by other studies which reported outdoor use as the drivers of the critical peaks that occur on the PD (Beal and Stewart, 2014; Cole and Stewart, 2013; Willis et al., 2011).

In single-residential dwellings, peak flows for $\mathrm{AD}$ reduced by $28 \%$ and $50 \%$ for Scenarios 3 and 4 respectively, while in multi-residential dwellings, they were lower by $35 \%$ and $52 \%$ respectively. In these two scenarios, the PH demand for both modelled PD were only slightly higher than the peaks on AD as the outdoor water use, which was the main cause of the peaks, was removed through source substitution. Overnight replenishment of mains water to the rainwater tank (Scenario 3) and the reliable supply of greywater (Scenario 4) met the full demand for the substituted mains potable end uses and directly influenced peak demand values. As a result, there were significant reductions in PH demand on the PD for single-residential and multi-residential dwellings, of 54\% and 51\% respectively for Scenario 3, and 64\% and $62 \%$ respectively for Scenario 4.

\section{Townhouse development example application}

\subsection{Water supply selection and design}

To better contextualise a water demand profile's application to a planned development area, a multiresidential development with a townhouse setting was considered. While it is practical to install efficient water appliances in all types of households, the choice of a source substitution measure depends on the feasibility of their application in a development. The reliability of rainwater tanks depends on a number of variables including climate, roof and tank and household water demand, with larger roof sizes and tanks providing a more reliable rainwater supply (Imteaz et al. 2011, 2012). For example, installing a communal rainwater tank is more feasible in a townhouse development than in a multi-storey apartment development due to the larger roof area per household, unlike the latter's smaller roof area to household ratio. Greywater reuse, even though it has a higher reliability due to constant supply, is only financially viable when implemented on a larger scale (i.e. one larger treatment system serve multiple dwellings), such as in a multistorey apartment development (Friedler and Hadari, 2006; Ghisi and Ferreira, 2007; Mourad et al., 2011). Hence, a communal rainwater setting was chosen for the townhouse development with the schematic shown in Fig. 7. 


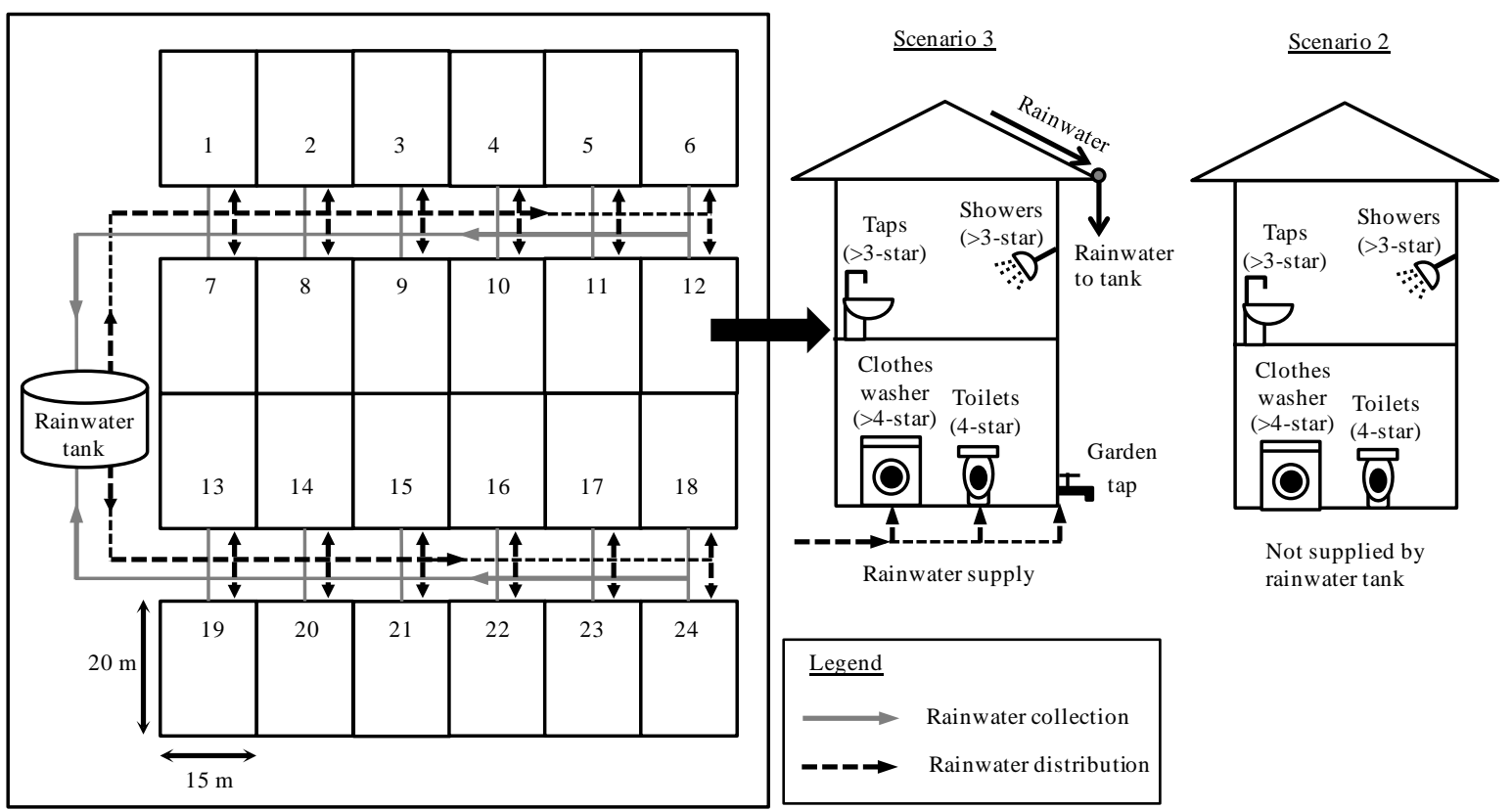

Fig. 7 Schematic of townhouse development with communal rainwater tank and water efficient appliances

\subsection{Volume tric reliability of communal rainwater tank}

A water balance was conducted using UVQ (Mitchell and Diaper, 2010) to determine the reliability of the communal rainwater tank for the 24-townhouses setting. The roof area for each townhouse was estimated to be $180 \mathrm{~m}^{2}$ (60\% of total plot size) with a $100 \%$ connectivity to the system and a runoff coefficient of 0.875 . Rainfall data recorded over a 20 year period (1994-2013) was obtained from the Bureau of Meteorology for Gilston Road, Nerang (Station ID: 040160) for the Gold Coast region. Rainwater tank demand of 59 L/p/d (Table 7) and an average household occupancy rate of 2.6 persons per household (OESR, 2012) were used as input data for the modelling. A communal rainwater tank of size $96 \mathrm{~kL}$ (4 kL per household) was chosen, with $10 \%$ of volume assigned for backup supply and dead zone. The resulting effective volume of $86.4 \mathrm{~kL}$ provided a high volumetric reliability of 92\%, indicating that overnight top-up would be required for approximately only 29 days in a year.

\subsection{Influence of rainfall on demand patterns}

Regular rainfall would ensure that $\mathrm{AD}$ top-up rates reduce by $92 \%$, as trickle top-up rates are averaged out over a year, while stored rainwater would potentially fully supplement the substituted end-uses on PD. This results in a demand pattern similar to a household reusing greywater. Conversely, long periods of drought would require trickle top-up on both $\mathrm{AD}$ and PD. The conceptualisation of Scenario 3's water demand patterns for regular rainfall (Scenario 3a - most likely case) and droughts (Scenario $3 \mathrm{~b}$ - worst case) for the 24-townhouses setting is shown in Fig. 8, along with modelled demand patterns for Scenarios 1 and 2. Again, it should be noted that the rainwater tank top-up requirements is set on timer to occur outside of typical peak periods (see Fig. 8).
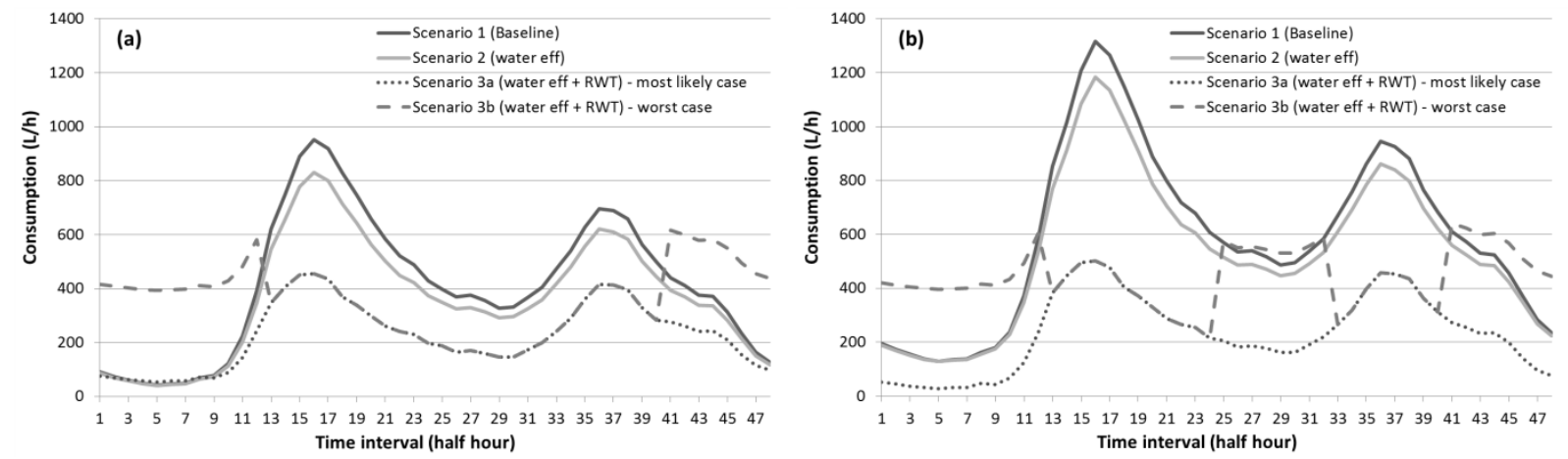

Fig. 8 Demand patterns for (a) AD and (b) PD within the 24-townhouses setting 
Table 9 details each scenarios peak demand (i.e. peak demand for entire 24 lot development in L/h) and percent reduction when compared to the baseline scenario. As shown in this table, installing higher rated water efficient appliances yields a $13 \%$ and $10 \%$ reduction in the peak demand value on the AD and PD, respectively. Much larger reductions are achieved when also installing the communal rainwater tank, with a $52 \%$ and $62 \%$ reduction in the peak demand on the AD and PD, respectively, for the most likely case (Scenario 3a). Even if the rainwater tank operated under worst case drought conditions (Scenario 3b), the peak demand is still lower by $35 \%$ and $51 \%$ on the AD and PD, respectively.

Table 9 Modelled peak demand and comparative reductions for the 24 lot townhouse setting

\begin{tabular}{lllll}
\hline & \multicolumn{2}{c}{ AD } & \multicolumn{2}{c}{ PD } \\
Scenarios & $\begin{array}{l}\text { Peak demand } \\
(\mathrm{L} / \mathrm{h})\end{array}$ & $\begin{array}{l}\text { Reduction } \neq \\
(\%)\end{array}$ & $\begin{array}{l}\text { Peak demand } \\
(\mathrm{L} / \mathrm{h})\end{array}$ & $\begin{array}{l}\text { Reduction } \neq \\
(\%)\end{array}$ \\
\hline Scenario 1 (baseline) & 951 & - & 1316 & \\
Scenario 2 & 830 & $12.7 \%$ & 1183 & $10.1 \%$ \\
Scenario 3a - most likely case & 455 & $52.1 \%$ & 501 & $61.9 \%$ \\
Scenario 3b - worst case & 616 & $35.3 \%$ & 640 & $51.3 \%$ \\
\hline †Note: represents a reduction in demand for contemporary scheme scenarios (2, 3a, 3b) with Scenario 1 (baseline)
\end{tabular}

\section{Implications for water dis tribution infras tructure planning}

Harnessing the benefits of high resolution smart meters to categorise flow data into the various end use categories allowed for a novel bottom-up approach to model the daily diurnal demand patterns of contemporary water schemes that incorporate a range of efficiency and water source substitution measures. Modelled demand patterns for households utilising water efficient appliances and source substitution measures provided strong evidence that there are considerable reductions in peak demand from the mains potable town supply. Water infrastructure network such as pumps and pipes are designed for peak demand conditions. The same infrastructure network is required to transport higher volumes of water each year as peak demand increases through the construction of new residential developments and also redevelopments with higher density housing through the subdivision of large land plots to smaller residential lots; such increases in demand necessitates trunk main augmentations. Hence, the application of water saving measures in new and high density developments would potentially defer or reduce system augmentation, and their subsequent involved costs, due to reduced peak demand. Furthermore, there is opportunity for considerable capital savings through the installation of smaller infrastructure (pumps, pipes, etc.) in new developments. Savings from recurring costs (e.g. maintenance and operation), would also be realised as lower pressure in the pipelines leads to reduced pipe failures and extended asset life, while energy costs is also reduced from running smaller pumps and through treating and transferring lower volumes of water.

The uptake of water efficient appliances and source substitution measures is predicted to rise in the future as water prices rise and the general population become more aware of the benefits of installing alternative technologies. As empirically demonstrated in this study, such installations have citywide benefits by reducing peak demand in the pipe infrastructure network on the $\mathrm{AD}$ and $\mathrm{PD}$, thereby providing substantial cost benefits.

Direct benefits in the form of reduced capital expenditure programs are realised by water utilities due to reduced peak demand since they can defer many costly infrastructure augmentations. Water infrastructure charges are the costs which utilities charge to land developers in order to recover part of the capital and ongoing costs for providing the necessary water services to the city. Given that this study shows that there are potential reductions in peak demand, which is the core driver of trunk main infrastructure augmentations, there may be some opportunities for formulating alternative water infrastructure charges policy for developers that implement proven water efficiency and source substitution measures. Water utilities could share some of their reductions in capital expenditure for augmentations by reducing these charges for those developments that implement savings measures, which will serve to promote further implementations across 
a city. Ultimately, this could create a 'win-win' relationship where utilities, developers and consumers all benefit from a more efficient water supply system.

\section{Conclusion}

The study modelled water demand patterns for the AD and PD for a range of potable water saving scenarios. Cluster scale analysis of indoor water efficient appliances was conducted to determine the level of reductions in consumption and peak demand when compared against the baseline scenario. Comparison of indoor water use revealed similar consumption patterns and peak demand occurring in the morning for single and multiresidential dwellings, while peak outdoor use was observed in the evening and morning for these two dwelling types, respectively. The size of a property was noted to be an influencing factor on outdoor water use with smaller properties using lower volumes than larger properties (Cole and Stewart, 2013). These analyses provided vital information in developing the bottom-up diurnal demand patterns for the water saving scenarios, as they affected the peak demand and their timings which are important in the design of the water infrastructure network.

Modelled water demand profiles of water efficient appliances and alternative water sources had the expected results of reduced peak flows. Developed consumption curves for households using higher efficiency appliances had a lower peak demand than baseline scenarios by $13 \%$ on the AD for both dwelling types and $6 \%$ and $10 \%$ on PD, for single and multi-residential dwellings, respectively. Also incorporating rainwater tanks and greywater reuse decreased peak demand by between $28 \%$ to $52 \%$ on the $\mathrm{AD}$ and $51 \%$ to $64 \%$ on the PD for both alternative water sources. These peaks can potentially be further lowered through the use of the highest efficiency rated indoor water appliances. A 24 unit townhouse in-fill development that included efficient appliances and a communal rainwater tank was compared against a baseline scenario to demonstrate the reductions in peak demand on the AD and PD. This illustrative application of the bottom-up derived end use patterns revealed that even under extended drought conditions, the contemporary development had much lower peak demand values than a typical development that only relied on town water.

If a large proportion of future in-fill developments utilise such water efficient appliances and install source substitution measures, they can significantly reduce the peak demand projections for a particular water supply zone trunk main. Such schemes will have direct implications on the design of the water infrastructure network, such as deferred system augmentations, infrastructure sizing and changes in water utilities' operations and maintenance schedules, along with their associated costs. Hence, it is crucial for water demand modelling practices to incorporate the demand reductions of such water saving measures, through harnessing the 'big data' available from smart water meters and autonomous water end use disaggregation informatics, in order to generate more realistic predictions of water demand patterns for these alternative development scenarios. Modelling using a one-size-fits-all demand template for each node of a network model is no longer sufficient in the modern water supply era. Future work will explore the life cycle demand reductions of a trunk main and the associated monetary benefits of large scale implementations of contemporary water supply schemes in a particular water supply zone that is experiencing population growth and higher density land redevelopment.

\section{Acknowledgements}

The authors would like to acknowledge the Australian Research Council (ARC) Linkage Grant scheme for providing funding to this project. We also acknowledge the financial and in-kind support of the City of Gold Coast. Participants of the various smart metering and water end use studies are acknowledged as their data was pivotal in order to generate the end-use level diurnal demand curves used in this study. 


\section{References}

Australian Bureau of Statistics (ABS), 2013. 4602.0.55.003 - Environmental Issues: Water use and Conservation, Mar 2013. Available at: http://www.abs.gov.au/ausstats/abs@.nsf/mf/4602.0.55.003, (accessed June 2014).

Ahmed, W., Brandes, H., Gyawali, P., Sidhu, J.P.S., Toze, S., 2014. Opportunistic pathogens in roofcaptured rainwater samples, determined using quantitative PCR. Water Research. 53, 361-369.

Aquacraft, 2010. Trace Wizard ${ }^{\circ}$ software version 4.1. 1995-2010 Aquacraft, Inc. Boulder, CO, USA.

Beal, C., Stewart, R.A., 2011. South-East Queensland residential end use study: Final Report, Urban Water Research Security Alliance, Brisbane, QLD. Technical Report No. 47.

Beal, C.D., Sharma, A., Gardner, T., Chong, M., 2012. A desktop analysis of potable water savings from internally plumbed rainwater tanks in South-East Queensland, Australia. Water Resources Management. 26 (6), 1577-1590.

Beal, C., Stewart, R.A., 2014. Identifying residential water end-uses underpinning peak day and peak hour demand. Journal of Water Resources Planning and Management. 140 (7): 04014008.

Booker, N., 1999. Estimating the economic scale of greywater reuse systems. Program Report FE-88. CSIRO Molecular Science.

Britton, T.C., Stewart, R.A., O’Halloran, K.R., 2013, Smart metering: enabler for rapid and effective post meter leakage identification and water loss management. Journal of Cleaner Production. 54, 166-176.

Carragher, B.J., Stewart, R.A., Beal, C.D., 2012. Quantifying the influence of residential water appliance efficiency on average day diurnal demand patterns at an end use level: A precursor to optimised water service infrastructure planning. Resources, Conservation and Recycling. 62, 81-90.

Chong, M.N., Umapathi, S., Mankad, A., Sharma, A., Gardner, T., 2011. A benchmark analysis of water savings by mandated rainwater tank users in South East Queensland (Phase 2), Urban Water Research Security Alliance, Brisbane, QLD. Technical Report No. 49.

Chrisotva-Boal, D., Eden, R.E., McFarlane, S., 1996. An investigation into greywater reuse for urban residential properties. Desalination. 106, 392-397.

Cole, G., Stewart, R.A., 2013. Smart meter enabled disaggregation of urban peak water demand: precursor to effective urban water planning. Urban Water Journal. 10 (3), 174-194

Cook, S., Sharma, A., Chong, M., 2013. Performance analysis of a communal residential rainwater system for potable supply: A case study in Brisbane, Australia. Water Resources Management. 27 (14), 48654876.

Cook, S., Sharma, A.K., Gurung, T.R., 2014. Evaluation of alternative water sources for commercial buildings: A case study in Brisbane, Australia. Resources, Conservation and Recycling. 89, 86-93.

Department of Infrastructure and Planning (DIP), 2008. Greywater guidelines for plumbers, A guide to the use of greywater in Queensland, Queensland Government, August 2008. Available at: http:/www.hpw.qld.gov.au/SiteCollectionDocuments/greywater-guidelines-plumbers.pdf $\quad$ (accessed June 2014]

Department of Health (DOH), 2010. Code of practice for the reuse of greywater in Western Australia 2010, Government of Western Australia, 2010. Available at: http://www.public.health.wa.gov.au/cproot/1340/2/COP\%20Greywater\%20Reuse\%202010_v2_130103 .pdf (accessed June 2014)

Domènech, L., Saurí, D., 2011. A comparative appraisal of the use of rainwater harvesting in single and multifamily buildings of the Metropolitan Area of Barcelona (Spain): social experience, drinking water savings and economic cost. Journal of Cleaner Production. 19 (6-7), 598-608.

East Bay Municipal Utility District (EBMUD), 2008. Water Smart Guide Book: a Water-use Efficiency Plan Review Guide for New Businesses. Oakland, California.

Ferguson, M., 2011. Rainwater tank monitoring report: a 12 month one-minute interval data study of rainwater tank savings and energy use for 52 real life installations, Sydney Water Corporation. 
Friedler, E., Hadari, M., 2006. Economic feasibility of on-site greywater reuse in multi-storey buildings. Desalination. 190 (1-3), 221-234.

Gato-Trinidad, S., Jayasuriya, N., Roberts, P., 2011. Understanding urban residential end uses of water. Water Science and Technology. 64 (1), 36-42.

Ghisi, E., de Oliveira, S.M., 2007. Potential for potable water savings by combining the use of rainwater and greywater in houses in southern Brazil. Building and Environment. 42 (4), 1731-1742.

Ghisi, E., Ferreira, D.F., 2007. Potential for potable water savings by using rainwater and greywater in a multi-storey residential building in southern Brazil. Building and Environment. 42 (7), 2512-2522.

Gold Coast Water (GCW), 2009. "Desired Standards of Service Review 2008”, GHD Final Report Rev 3, October 2009

Grey, D., Sadoff, C.W., 2007. Sink or Swim? Water security for growth and development. Water Policy. 9 (6), 545-571

Gurung, T.R., Sharma, A., 2014. Communal rainwater tank systems design and economies of scale. Journal of Cleaner Production. 67, 26-36

Gurung, T.R., Stewart, R.A., Sharma, A.K., Beal, C.D., 2014. Smart meters for enhanced water supply network modelling and infrastructure planning. Resources, Conservation and Recycling. 90, 34-50.

Hall, M., 2013. Review of rainwater tank cost effectiveness in South East Queensland. Urban Water Research Security Alliance, Brisbane, QLD. Technical Report No. 105.

Imteaz, M.A., Ahsan, A., Naser, J., Rahman, A., 2011. Reliability analysis of rainwater tanks in Melbourne using daily water balance model. Resources Conservation and Recycling. 56 (1), 80-86.

Imteaz, M.A., Rahman, A., Ahsan, A., 2012. Reliability analysis of rainwater tanks: A comparison between South-East and Central Melbourne. Resources Conservation and Recycling. 66, 1-7.

Lee, M., Tansel, B., Balbin, M., 2011. Influence of residential water use efficiency measures on household water demand: A four year longitudinal study. Resources, Conservation and Recycling. 56 (1), 1-6.

Li, F., Wichmann, K., Ottenpohl, R., 2009. Review of technological approaches for greywater treatment and reuses. Science of the Total Environment. 407, 3439-3449.

Loh, M., Coghlan, P., 2003. Domestic water use study in Perth, Western Australia 1998-2001. Perth, Australia: Water Corporation.

Lucas, S.A., Coombes, P.J., Sharma, A.K., 2010. The impact of diurnal water use patterns, demand management and rainwater tanks on water supply network design. Water Science \& Technology: Water Supply-WSTWS. 10 (1), 69-80.

Makki, A.A., Stewart, R.A., Panuwatwanich, K., Beal, C., 2013. Revealing the determinants of shower water end use consumption: enabling better targeted urban water conservation strategies. Journal of Cleaner Production. 60, 129-146.

Mitchell, G., Diaper, C., 2010. UVQ User Manual. CMIT Report No. 2005-282. CSIRO. Available at: http:/www.csiro.au/Organisation-Structure/Flagships/Water-for-a-Healthy-Country-Flagship/UrbanWater/UVQ.aspx (accessed June 2014)

Mourad, K.A., Berndtsson, J.C., Berndtsson, R., 2011. Potential fresh water saving using greywater in toilet flushing in Syria. Journal of Environmental Management. 92 (10), 2447-2453.

Nguyen, K.A., Stewart, R.A., Zhang, H., 2014. An autonomous and intelligent expert system for residential water end-use classification. Expert Systems with Applications. 41 (2), 342-356.

Office of Economic and Statistical Research (OESR), 2012. Population and Dwelling Profile; South East Queensland, Queensland Government, April 2012. Available at: http:/www.oesr.qld.gov.au/products/profiles/pop-housing-profiles-reg-planning/pop-housing-profilesseq.pdf (accessed June 2014)

Queensland Water Commission (QWC), 2010. South East Queensland water strategy, The State of Queensland, City East, Queensland. 
Schlunke, A., Lewis, J., Fane, S., 2008. Analysis of Australian opportunities for more water efficient toilets, [prepared for the Australian Government, Department of the Environment, Water, Heritage and the Arts], Institute for Sustainable Futures, University of Technology, Sydney.

SEQ Code, 2013. South East Queensland water supply and sewerage design and construction Code, South East Queensland Code, Queensland. http:/www.seqcode.com.au/storage/2013-07-01\%20\%20SEQ\%20WSS\%20DC\%20Code\%20Design\%20Criteria.pdf (accessed June 2014)

Sharma, A.K, Gray, S., Diaper, C., Liston, P., Howe, C., 2008. Assessing Integrated Water Management Options for Urban Developments - Canberra case Study. Urban Water Journal. 5 (2), 147-159

Talebpour, M.R., Sahin, O., Siems, R., Stewart, R.A., 2014. Water and energy nexus of residential rainwater tanks at an end use level: Case of Australia. Energy and Buildings. 80, 195-207.

Tjandraatmadja, G., Pollard, C., Sharma, A., Gardner, T., 2011. Dissecting rainwater pump energy use in urban households, In: Science Forum and Stakeholder Engagement: Building Linkages, Collaboration and Science Quality, (eds) Begbie DK and Wakem SL, Urban Water Security Research Alliance 2011, Brisbane, Queensland, pp. 35-40.

Umapathi, S., Chong, M.N., Sharma, A.K., 2013. Evaluation of plumbed rainwater tanks in households for sustainable water resource management: a real-time monitoring study. Journal of Cleaner Production. 42, 204-214.

Willis, R.M., Stewart, R.A., Williams, P.R., Hacker, C.H., Emmonds, S.C., Capati, G., 2011. Residential potable and recycled water end uses in a dual reticulated supply system. Desalination. 272 (1-3), 201211.

Willis, R.M., Stewart, R.A., Giurco, D.P., Talebpour, M.R., Mousavinejad, A., 2013. End use water consumption in households: impact of socio-demographic factors and efficient devices. Journal of Cleaner Production. 60, 107-115.

Zhang, Y., Grant, A., Sharma, A., Chen, D., Chen, L., 2009. Assessment of rainwater use and greywater reuse in high-rise buildings in a brownfield site. Water Science \& Technology. 60 (3), 575-581.

Zhang, Y., Grant, A., Sharma, A., Chen, D., Chen, L., 2010. Alternative water resources for rural residential development in Western Australia. Water Resources Management. 24, 25-36. 